Fullagar, S \& Small, I. (forthcoming, 2018). Writing recovery from depression through a creative research assemblage: Mindshackles, digital mental health and a feminist politics of self-care. In Parry, D, Johnson, C \& Fullagar, S. (Eds). Digital Dilemmas: Transforming Gender Identities and Power Relations in Everyday Life, Palgrave: London.

(This is a preprint author version and some changes may occur in the published chapter).

\title{
Writing recovery from depression through a creative research assemblage: Mindshackles, digital mental health and a feminist politics of self-care
}

\begin{abstract}
In this chapter we write through an academic-arts collaboration, or creative research assemblage, to explore the dilemmas surrounding cultural representations of women's experiences of recovery from depression. We focus our discussion on the Mindshackles website that was created by, lesha, to offer 'personal stories about reclaiming life from mental ill health.' By documenting diverse stories with photographic images, film and sound, Mindshackles makes visible the everyday leisure practices that women enact as self care in recovering their sense of aliveness. We explore feminist questions about how documentary practices can shape digital representations of mental health in ways that both reveal and conceal issues of gender and power.
\end{abstract}

\section{Introduction}

Mindshackles volunteers are gay, straight and people who don't want to be labelled. We are entrepreneurs, unemployed and nine to fivers. One thing unites us, we 
have all had significant problems with our mental health during at least one point of our lives, or we care for somebody else who has, and we have made it through the other side. Some of us continue to experience ongoing mental health problems but each time we find a way to get out of bed and live another day. The majority of Mindshackles volunteers are people with a deep passion for something or someone and that aids our recovery. We want to tell our stories as part of our own journey to self acceptance and ongoing recovery and to help others (and their loved ones) understand that they are not alone. Many of us have used our participation in the project to start conversations with our own families and friends about mental health. (Mindshackles, Volunteers).

Trisha: 'When I come off the dancefloor I think, 'That was a good night, oooh I danced my socks off!' *laughs* I've cleared my mind, whatever problems I had before it doesn't seem to really bother me, once l've come off. I have to say, my mind's blank, I don't think of anything. A lot of the music's from Brazil, Columbia, Italian, Portuguese, it's a different language but music is universal. You don't have to be able to understand exactly what they are saying to be able to dance to the music. I'm just on that dance floor and that's that. I'm just listening to the music thinking, 'Oooh that's a lovely record,' *laughs* 'Oooh I like that record. Let's find somebody to dance with'. (Trisha: $\underline{\text { Rhythm of joy, Mindshackles) }}$

Trisha's story on the Mindshackles website provides us with a unique point of departure for exploring how both leisure and digital practices can creatively transform public understanding about mental (ill) health and the possibilities of recovery. Our 
chapter is written through an academic-arts collaboration, or "creative research assemblage' (Fox \& Alldred, 2016; Fox 2015), to explore the dilemmas surrounding cultural representations of women's experiences of recovery from depression. We focus our discussion on the Mindshackles website that was developed by lesha, to offer 'personal stories about reclaiming life from mental ill health'. As a documentary photographer (and teacher, parent, youth advocate), lesha created the site in 2013 as means of using digital technology to share the experiences and voices of different people to publicly counter the stigmatisation surrounding mental health issues. The Mindshackles site and its associated twitter handle offer an alternative, creative approach that seeks to capture and evoke everyday moments significant in the ongoing experience of recovery for different women (and also some men). It was Mindshackles' focus on everyday leisure practices in peoples' recovery that began our conversations and connected our creative, personal, political and academic interests. In our dialogue we identified connections that emerged in our own distinct research and creative practices around different notions of recovery. Later in the chapter we take up these threads of conversation as a means to collaboratively write through some of the digital dilemmas in producing creative-activist-academic knowledge. We focus largely on one personal story and photograph - Trisha: rhythm of joy - from the Mindshackles site as an evocative example for our discussion.

In writing this chapter we drew inspiration from the traditions of creative analytic practice (Sjollema \& Yeun, 2017; Berbary, 2015; Parry \& Johnson, 2007; Richardson, 2000), arts-based methods (Boydell et al., 2016), post-humanism (Fox, 2015; 2012; Duff \& 
Sumartojo, 2017) and post-qualitative inquiry (St. Pierre, 2014), to show how creativeactivist-academic collaborations can generate different ways of 'doing' both digital and gendered mental health. Simone approached the Mindshackles project with a feminist interest in the possibilities of creatively articulating a politics of self-care that invites different ways of engaging with personal stories as political and affective sites of social change (on the politics of self-care, see Fullagar, 2008b). Critical insights from feminist theories of embodiment, affect theory, and digital assemblages provide a way of exploring the micropolitics of leisure and wellbeing and troubling normalised biomedical perspectives on mental illness/health as an individualised issue. lesha was interested in alternative representations of mental health, where mental ill health status was known and accepted but not actually the focus of the digital representations. The project gave the volunteers an opportunity to present a version of themselves beyond their mental health status that focused on experiences that provided them joy.

\section{Creativity, leisure and recovery: Digital mental health practices}

We draw upon Fox $(2012,2015)$ and Duff and Sumartojo's (2017) notion of a creativityassemblage to conceptualise Mindshackles as a digital project of cultural activism. We employ different representational practices to unsettle the binaries of real/representation, fact/fiction, digital/analogue, labour/leisure and mind/body. In this way we position the writing-reading of digital sites as practices of 'cultural making' (Swist et al., 2016), that generate creative and critical forms of entanglement; as we write or read we are also written through creativity as an embodied flow of affective meaning. Writing is not simply a rational, objective practice of producing knowledge that 
presumes to 'represent' a world that pre-exists it. Moving beyond a representational logic, writing-reading are understood as material practices through which a range of affects act upon us, as we write to affect others (pleasure, joy, sadness, anger, shame etc). In contrast to notions of creativity that privilege cognition, individual genius or only specialised artistic practice, Fox (2015) argues more broadly that creativity is a profoundly affective aspect of everyday relations and embodied capacities that involve both human and non-human elements.

As a site for digital mental health promotion, Mindshackles produces an approach to recovery that emphasises the experience of creating-becoming that is oriented around diverse pleasures and leisure practices (as distinct from 'expert' biomedical definitions of symptoms, diagnoses or treatment protocols). 'Readers/users' are engaged through affective and sensory relations that materialise through text and images. We can feel drawn to individual stories, compelled or repelled by certain images that move us (pleasurably, shamefully, empathically) as we connect, disconnect, react or shun the everyday emotional lives of others that are grouped collectively (but not bound by diagnostic illness categories) around 'recovery' as a process of becoming. Digital representations are thus read through the body, evoking memory, senses and diverse affects that can produce new capacities, relations and hence forms of agency. As Fox (2012, p. 499) states, 'Affects are "becomings" (Deleuze and Guattari, 1988: 256) that represent a change of state of an entity and its capacities (Massumi, 1988: xvi): this change may be physical, psychological, emotional or social.' 
The experience of contemporary subjectivity and common mental health issues is profoundly shaped by diverse assemblages that produce meaning across physical and digital space-time. The sense making process of understanding distress is often mediated by digital practices, such as, searching Google in waiting rooms, Instagram images on the bus, writing-reading blogs on chemical imbalances or lifestyle balance, and engaging with various platforms for sharing stories of recovery. As Fox (2012, p. 500 ) argues these ways of coming to know one's own emotional state in terms of 'depression' are produced through, 'the affective flows associated with biomedicine territorialise those involved in a health-care consultation, transforming a sick person into a patient, the professional into a healer and signs and symptoms into a disease...'. Many digital mental health interactions are heavily shaped by biomedical forms of expertise and recovery from symptoms, rather than opening up capacities for creativity and different affective responses (pleasure, anger, joy, belonging, love, etc). This is not to deny the affective power of 'diagnoses' to produce relief for some, a sense of legitimacy for others, and access to services that are highly regulated (and in some cases profitable) by the State and market forces. However, the affective relations of diagnostic cultures are most often bound up with 'compliance' with professional expertise, rather than creative capacities to reconfigure boundaries of knowing and being.

Rather than position the humanist subject at the centre of creative processes, assemblage thinking understands creativity as relational, emerging through human and non-human encounters and affects. Duff and Sumartojo (2017, p. 419) theorize the 
creative assemblage as productive of capacities - 'a more or less temporary mixture of heterogeneous material, affective and semiotic forces, within which particular capacities for creativity emerge, alongside the creative practices these capacities express'. In this way we can think about how the affective relations of creativity are mediated through 'inextricable intertwinings of humans and their data' in broader digital assemblages (mobile and wearable devices, social media sharing, algorithms and data harvesting)" (Lupton, 2017, p. 3). It is this creative potential of digital practices to re-present and reconfigure the materiality of meaning about depression and recovery that we seek out as a means of generating a range of affective capacities in public culture.

Feminist explorations of women's mental health have also identified how creativity embodied through different leisure practices contribute to the conditions of possibility as one recovers from depression (Lafrance, 2011; Parry, 2013; Fullagar, forthcoming, 2008a,b). Drawing upon different theorisations of power (eg., constraints, ideology, discursive and affective relations) these feminist approaches have examined the gendered conditions of possibility that enable women to move beyond the debilitating effects of depression (on the relationship between masculinity, digital mental health and play see the chapter by Swist \& Collin in this collection). In Simone's analysis of digital mental health sites, gender was often ignored and women's experiences essentialised in representations of depression (Fullagar, 2008a). In relation to experiences of recovery, leisure figured as a an everyday site through which women negotiated their sense of entitlement, creativity and practices of self-care beyond a heteronormative 
masculinity that would assume the 'giveness or naturalness' of the right to free time, space and freedom. She wrote,

For many women recovery was linked to a sense of creativity, which they articulated as finding a voice and space for themselves. This creative sense of self manifested in pursuits such as journal writing, poetry, storytelling, writing letters to newspapers or friends, art classes or art at home, appreciating the beauty of nature, and performing in community theatre or the local circus group. (Fullagar, 2008b, p.46)

While women's creativity was regulated and constrained, leisure practices also worked as "counter-depressants" embodying particular transformative affects, and effects, in relation to destabilising gender norms (Fullagar, 2008b, p.37). Feminist research understands the relation between creativity and recovery to be not just personal, but also produced through the sociocultural, economic, political contexts of advanced liberal, capitalist and patriarchal societies as these forces act through our emotional lives, capacities and opportunities for leisure.

Moving the interpretivist focus of this earlier work into the more feminist oriented and posthumanist direction of this chapter, we return to assemblage thinking to offer a way of understanding how digital entanglements bring into relation human and non-human elements, objects and medical, work, leisure, home and self-care practices (see also Fullagar, forthcoming; Berbary, 2015; Kumm \& Johnson, 2017). As feminists have long argued, women's work and leisure lives, bodies and emotions are entangled in biopolitical formations, patriarchal practices and global flows (Lafrance, 2011; Ussher, 
2011; Fullagar, 2008; Teghtsoonian, 2009; Stoppard, 2000). These entanglements include a diverse assortment of human and nonhuman, individual, corporate and state agencies. For example, the marketing practices of Big Pharma interact with the prescribing and diagnostic practices of doctors, and individualised self-help discourses in popular and social media. Mental health promotion and treatment practices largely ignore, and hence discount, gender relations and other social conditions that undermine emotional, financial and personal well-being.

If gender appears in discourses of mental health and illness it is often reified as a biological or identity category across a rapidly expanding range of 'digital solutions' that seek to address gendered mental health problems such as depression and anxiety (more women are diagnosed than men)(McManus et al., 2016). In the United Kingdom, to alleviate growing pressure and cost in the national health system digital technologies are positioned as a key response to the demand for psychological therapies and medication (anti-depressants are not advertised and must be prescribed by General Practitioners and/or Psychiatrists (McManus et al., 2016). We are witnessing the growth of various digital practices and platforms that aim to educate and improve self-care and social support. For example, mental health promotion websites and digital apps promote the 'five ways to well-being', circulate anti-stigma messages, encourage self-diagnosis through quizzes and urge self-management of mood and behaviour via gamified therapies (Mood Gym) (see Fullagar, Rich \& Francombe-Webb, 2017; Rich \& Miah, 2017). 
While they may involve play like forms of engagement (see Swist and Collin's chapter in this collection), there is a distinct lack of critical content or context when it comes to making visible the micropolitics of personal distress, especially as they are connected with inequalities related to gender, class, sexuality, ethnicity, etc. The creative imagination of digital mental health promotion and pedagogy is highly normalised and shaped by biomedical notions of personhood where illness is a problem residing within the 'self'. In response, we argue that an understanding how creative leisure and digital representations are assembled across various practices and spheres of life, can work to make the gendered relations of affect more visible as forces that regulate subjectivity and open up other possiblities of becoming (see Duff, 2014; Braidotti, 2013; Fullagar, 2017; McLeod 2017). As one digital practice of cultural activism, Mindshackles creates a public space where everyday 'lay' accounts circulate personal stories as different kinds of knowledge beyond the normalised focus of 'expert' accounts that focus on things like brain dysfunction, medication, cognitive behavioural therapy and individualised prescriptions for healthy living.

In the following section we present one particular narrative and photograph that is featured on the Mindshackles website as it articulates recovery through a visceral sense of affective relations and 'aliveness' (Fullagar \& O'Brien, 2012). Trisha, who identifies as a Black British woman of Afro-Caribbean descent, is in her 50s. For us the account evokes an experience of recovery that is sustained through pleasurable rhythms of dance, music and friendship, entangled with issues about stigma and the invisibility of depression, as well as the stress of work and divorce. We present the narrative in its 
entirety with a subsequent conversational dialogue through which we explore questions about creative-academic-activist processes of digitally re-presenting women's experiences.

\section{Trisha: Rhythm of joy}

Whatever problems I had before don't seem to bother me.

I'm just on the dancefloor and that's that.

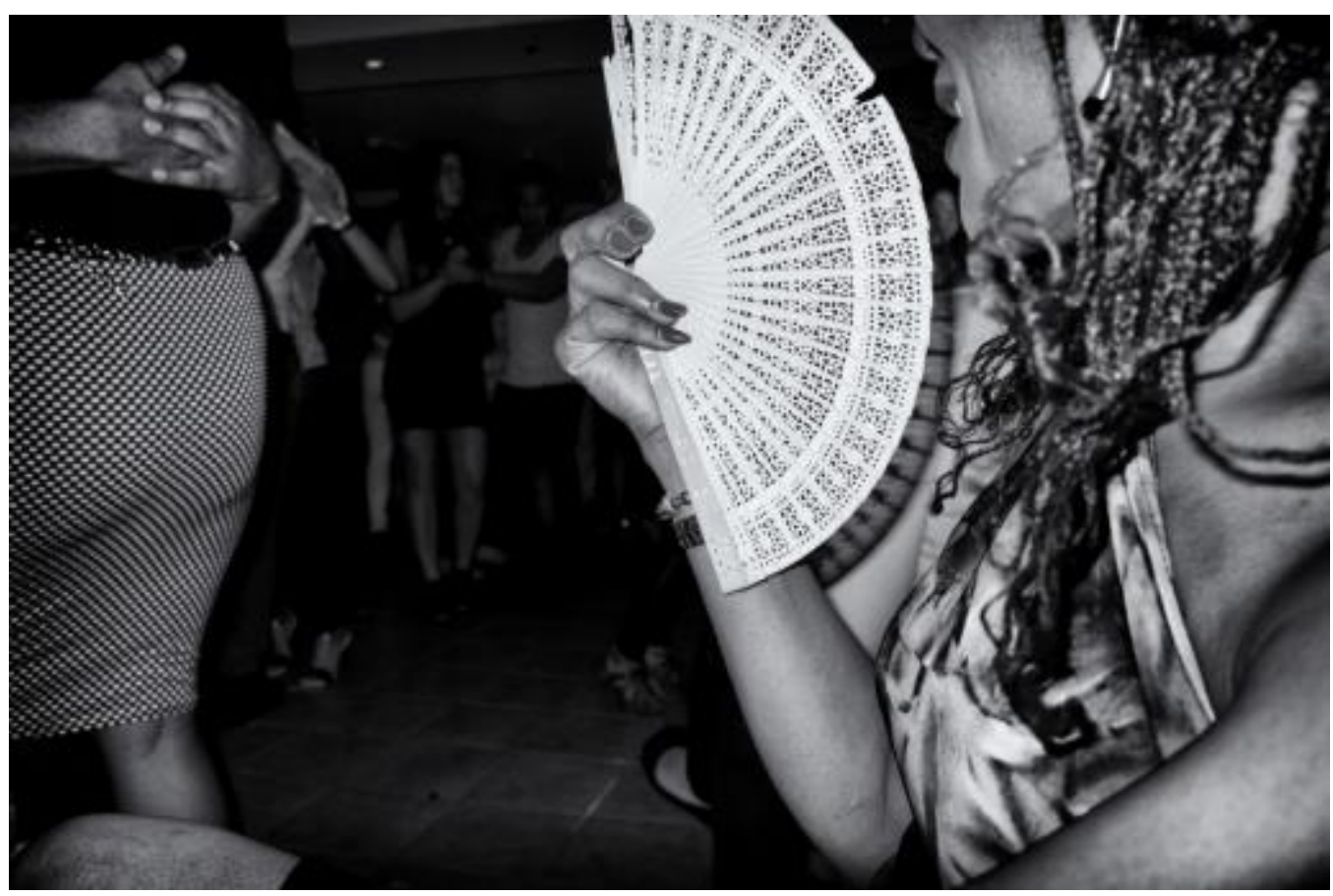

Photo: lesha Small

When I'm on the dance floor, the mind might feel tired but the bones don't, so I find that it's a stress release for me. It's a form of expression as well and the dancing replaces going to the gym. Financially, it's not expensive so you can go on a regular basis and 
I've met so many different people from all walks of life. Some who have experienced divorce, going through the change of life, and the age range is between 30s and 70s. I met a guy in his 70s and he's been dancing for years. Unfortunately, he lost his wife some years back. They used to dance together and he continued dancing. So the dancing knows no barriers. It's important for me, I quite enjoy it really.

You don't have to have a partner to go with [because in classes] they tend to mix you around from one person to the other, so you will get to dance with someone, they make sure you go around in a circle when you do La Reda. It's good for the figure and it's good for the mind, so what's happening is you are getting benefits for the whole body and you're meeting people at the same time. People from all different cultures and walks of life. Well, I have a really good friend, Karen, she was there more than 10 years ago, dancing, and she was on her own. I met her and we became really close friends.

I've always been dancing. I used to go once a month when the children were growing up, or once every two months. It's a bit difficult when you're working full time and [have] growing children but when the they started to get older... it wasn't just that... when I started to have difficulties in my first marriage I started to get back into it. I realised the benefits certainly helped me through my divorce. You can get dressed up as well and it's a feel-good factor. I started to go and I thought, 'Hang on a minute, this is something I enjoy and I don't need to have anybody to go with.' So that's when I started going every week. I think probably about 15 years ago. I don't drink or smoke [so] I save my money for dancing. *Laughter. * 
At one point I was going of three of four times a week but now I'm a bit tired and I'm doing more studies again. I changed my profession some years ago and, after 30 years of being in the office, I now work with people with disabilities, so now l've gone to long hours and shift work. I definitely go about once a week.

At the moment l'm learning kizomba, not zumba, which is like African tango it's a lovely dance, very sensual, very beautiful. It reminds me a little bit of soca [a music and dance style from the Caribbean]. If you watch the dancing, there's an art to it. If a guy's really good he can make you look absolutely fantastic, professional. At the moment, everywhere I go now, they don't just do the salsa, they do the kizomba. It's very popular, especially with the men, because it's a slow dance and they are completely in the lead. With salsa the lady has a 5 minute window where she can shine but with kizomba you are totally reliant on the guy so he's in charge and I think a lot of the men like that! *laughter*

Hubby goes sometimes as well but I tend to go with my girlfriends. I've met so many people and we just text each other. In the week I tend to go on my own because we have different commitments, it's difficult to get everybody together at the same time. I usually come home, get dressed, get showered and then go out dancing.

People found it very difficult to believe that I could get quite low because l'm such a happy person all the time. I would say be mindful of people around us. Sometimes when you see people putting a brave face on there's a lot going on, those are the people you 
have to watch because they never cry out until it's too late. Nobody is immune to depression, it can come at any time in your life and also any age. I'm at a good place in my life at the moment but, quite frankly, I'm one of the lucky ones. I have children, I have a husband, I've been married before, I've got a roof over my head. I thank God every day.

\section{A conversation about digital cultural making}

Simone: I really like how you have composed this piece as there is such a sense of movement and embodied pleasure. It evokes that sense of vitality or aliveness that Trisha embodies. You echo what Ahmed (2004) wrote about how, 'Pleasures open bodies to worlds through an opening up of the body to others...spaces are claimed through enjoyment' (p. 164). So, how did this come to be a preoccupation in your desire to create different ways of understanding recovery?

lesha: Leisure and pleasure were actually central to the Mindshackles project when I conceived it. Art and a regular photography practice really helped me to overcome a very difficult time in my life. I wondered what hobbies or enjoyable practices other people used to help them through times of depression.

So photography was a way of seeing those intangible aspects of our recovery experiences that are important to feeling alive.

Simone: You capture the complexity of individual stories through particular shared moments that don't feel 'confessional'. And the photographs reverberate with your quite poetic rendering of your participants' words. What process do you go through to create stories and evoke a sense of aliveness? 
lesha: I was inspired to create the multiple narrative site for Mindshackles by a documentary series called "Small Town Inertia" that was created by a photographer, Jim Mortram, whom I met initially via social media. The process has evolved over time as I have become more skilled as a photographer and storyteller through collaborating with my volunteer participants.

Simone: Was this about learning to listen, as well as see differently? lesha: Well at the very beginning of Mindshackles (or Into the Light as it was then) I saw myself as a photographer and it was visually driven. Now I consider it narrative based and use a combination of whatever media best works to tell my volunteer's story. For my first interviews I asked volunteers what depression (and other key words) meant to them. They did brain storms or mindmaps for me in my notebook which I intended to use on the website.

Then, just by chance, I decided to record a brief conversation that I had with one of my early volunteers, Gwen, about her mindmap. It was just on my iphone because that's what I had with me. When I was writing a few days later, I listened to our impromptu interview and found Gwen's own words really powerful. Rather than paraphrase, I wanted those actual words to write through me. That was how the style for Mindshackles was born - all posts are edited versions of participants actual words from a conversational style interview, with nothing obvious from me apart from occasional [square brackets] for clarity or to anonymise something.

Simone: So how did you engage people in the process of telling their stories? lesha: The first interviews explored fairly loose questions and l'd just turn up to a venue they had chosen (the interview and photograph locations are always the 
volunteer's choice) only knowing what their leisure pursuit was and that they had suffered from depression (or similar) at some point. l'd then record the evolving conversation but later, I arranged 'pre interviews' where we'd have a freeform (unrecorded) discussion over the phone before I came to visit. I would then offer my thoughts on an interesting angle to explore while volunteers also suggested ideas for photographs, or a particular location.

It became much more co-constructed. They felt more at ease with me and how they would be represented. We would spend anywhere from 1-3 hours and it was often at their own homes. After the interview I take photographs, as I've found people are much more relaxed then and it makes for a more pleasant experience for them and well as better photographs. Listening and responding was more important to me than sticking to a script.

For Trisha's post I went with her to her dance night at a Kizomba club in South West london took photographs while she danced and socialised. I also learnt some dance moves and got involved myself.

Simone: Having danced your way into this sense of the 'aliveness', how then do you write it up?

lesha: I transcribe the interview recording then I edit it by hand from a paper print out to capture the essence of the volunteer. I rearrange sections for a more coherent narrative flow (on paper conversations aren't always linear or easy to follow). I may cut out repetition, or tangential lines of thought and edit out stories about other people. I've cut parts that refer to family members, for example, as I don't feel I have 
permission to tell those stories. All volunteers have consented and signed media release forms. I don't add anything to the narrative that wasn't said at the time.

After the narrative is complete, I select the most complimentary photographs that I feel will portray the person in a way they will feel happy with. I also select strong sections of the interview to include as audio in the posts as I want readers to hear the volunteers actually speak. I often have my long time collaborator MC Small Mercies construct a custom piece of music that is inspired by their photographs and voice.

I send a link to the volunteer once the post is complete and they are able to comment on it. I remove anything they don't want, but I can only remember this happening twice. One volunteer asked for a particular picture she thought was triggering to be removed. Another volunteer once asked me to anonymise a place.

Simone: If we accept that each step (interviews, telling and re-telling stories and taking/selecting photographs) produces a particular version of the person's experience, how do you find people deal with the issue of stigma and sharing their story publicly?

lesha: I try my best to introduce elements of co-construction and participant control at various points. We only proceed to the next stage if they are happy with the process. We talk about possible approaches to the photography and interview topic together. l've found that when people are happy to say yes to Mindshackles it is often a time in their personal journey when they are ready to be more open about their mental health history or present.

Several of my volunteers have used their Mindshakles posts as an opportunity to 'come out' to their personal networks about their mental health via sharing on Facebook 
or equivalent. Much to my surprise, all of my volunteers so far have chosen to use their real names.

Simone: Going back to Trisha, it is not often we read about the recovery stories of older, Black women where there is a focus on the public pleasures of dance embodied movement, socialising, music, creativity etc. There is also a lot that remains unspoken in public discourses about mental health concerning the intersectional experiences of racism, sexism, classism, heterosexism, nationalism etc that shape depression and recovery.

So, given that we are both women and queer, but from quite different cultural backgrounds, I'm interested in how your thinking and practice is evolving with respect to ways of articulating the personal-political context of recovery beyond representations of women as overly 'heroic' individuals or only 'victims' of oppression?

lesha: Sadly, recovery stories and media or artistic representation about Black people and especially Black women are told by people who are observing their experience, but will never live it in its fullness. I am a woman and I am Black. I also happen to be queer. Neither of these were at the forefront of my mind when I first started Mindshackles. Over time I just contacted people who I had access to in my personal, professional and extended network. As a Black, queer woman these networks are probably more diverse than the average white male photographer or documentarian.

I also feel that, as a Black woman, the totality of the Black female experience is not exotic, alien or unusual to me. I don't need to project an idea of Black womanhood pre-conceived in ignorance. Sure, I see people being strong and heroic, but I also see 
them laughing, sometimes crying. I see them cooking, I see them living their day to day lives and having fun. I see women who have the structures of society against them, but I don't automatically see them as victims. Mindshackles is about representing people beyond their mental health label. And I suppose that in doing that I'm representing people beyond their gender, racial or sexuality stereotypes without explicitly setting out to do so.

Simone: This queer perspective resonates through our creative collaboration to unsettle the fixity of mental health and other identities. I'm drawn to how Mindshackles site creates a digital space for individuals to connect in multiple ways through the personal stories, images and possibilities for recovering-becoming. As you say these posts are also performative in particular ways as 'coming out' stories. They provide a digital archive of everyday practices (dancing, cooking, sport, art) that is important for sustaining a liveable life, as Judith Bulter says (2014). The site evokes a sense of aliveness that cannot be predefined or normalised, but emerges against stigma and shaming practices that 'stick' to mental health issues (and marginalised identities) that Sara Ahmed writes about $(2004,2017)$.

\section{Complexity of personal narratives for digital publics}

The question of how mental health issues are culturally imagined, felt and represented becomes increasingly important for challenging the individualisation of responsibility for prevention and recovery. In relation to the digital assemblage of recovery stories, Mindshackles invites a different kind of affective engagement that differs from the pedagogical intention of many mental health sites to improve literacy (Fullagar, Rich 
and Francombe-Webb, 2017). Yet, the sharing of personal stories via digital media is not simply a 'better' alternative for learning about recovery. As Grey (2017) has argued many personal representations of people with lived experiences of mental ill health in public campaigns participate in a process of 'benevolent othering' that negatively stereotypes and obscures the social context. In this sense, all digital stories are performative (and have political affects) in that they render experiences and the context that shapes them visible or invisible in particular ways. For example, personal stories situated within biomedically oriented professional websites (such as, Jon's story on

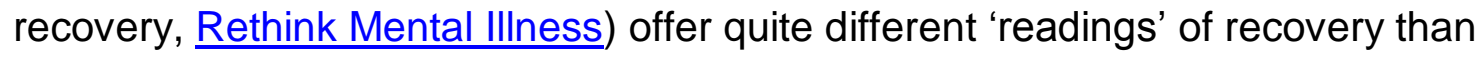
personal stories shared through crowd sourced sites that offer a wide range of 'unedited' experiences (such as, $\underline{A}$ Day in the Life). Jon's story of 'patient experiences' articulates a clinical view of normative recovery in terms of compliance with treatment protocols (therapy, medication and self-care). In contast, the Day in the Life site opens up diverse recovery practices that trouble the dominance of biomedical explanations (the negative affect of treatment is also visible).

As Swist et al., (2017) have argued cultural making through digital practices can contribute to diversifying and challenging individual, organisational, policy and pedagogic conversations. Simply trying to increase mental health literacy and helpseeking to comply with medical and therapeutic discourses fails to understand the entanglement of the political and personal in the production of 'public feelings' through categories of depression, anxiety etc. (Cvetkovich, 2012). Mindshackles offers a creative rendering of individual experiences as documented stories and images to 
evoke different ways of engaging with mental health issues through leisure practices (involving sensory bodies, objects, spaces etc through cooking, sport, dancing etc). As a creative digital platform it opens up questions about experiences of emotional distress and well-being beyond the dominant logic of our diagnostic (and gender neutralising) culture (Fullagar \& O'Brien, 2014; Healy, 1998). The site simultaneously produces multiple stories and a collective re-presentation of recovery that is not overtly connected to an affirmation or rejection of identity politics surrounding mental health and illness (patients, service users, survivors or mad movements), nor those of feminist, Black, queer, crip or other identity politics (on the tensions of experiential authority see, Voronka, 2016).

This is not to say that Mindshackles is apolitical, rather the points of connection are more diffuse, arising through affects, identifications and practices that can open up multiple possibilities for change. One of the challenges arising from our conversations, is how to retain the openness of identification when public accounts of recovery from mental health are often articulated as 'coming out' stories that have a range of affects and effects on identity formation (Ridge \& Ziebland, 2012). There is an on-going dilemma here about how we make visible the digital traces that forge connections across the politics of mental health, feminist, Black, queer and related spaces.

While the narratives are personalised accounts, they also speak to the micropolitics of women's emotional lives that regulate how experiences can be voiced that may otherwise remain unheard. The value of joy and pleasure in the everyday practices of 
self-care in women's recovery is a unique feature of the stories and images on Mindshackles. In relation to Trisha's story, the pleasures of dance are positioned as significant in her practices of self-care. In this way she articulates a sense of entitlement to leisure, her own friendship networks and an embodied time-space that resists gendered, racialised and heternormative notions of womanhood as defined primarily through care for others/self-sacrifice. Yet, notions of self-care are far from simply being 'activities', rather through the enactment of leisure practices women negotiate the contradictions of gendered embodiment. Tricia's account of dance echoes Sara Ahmed's (2017, p.248) reflections in Living a Feminist Life where she says 'A dancing feminist body, a dancing lesbian body, dancing black and brown bodies; the affirming of how we inhabit bodies through how we are with others... Dance can be how we embrace the fragility of being thrown.'

Kisner has recently argued (2017) that the hashtag \#selfcare rose to popularity in America during 2016 through representations of individualised practices (from face masks to creating 'me' time) of empowered (white, middle class, heteronormative) femininity that intertwined digital media with expanding markets. Self-care has also been reclaimed by Black feminists at different historical moments to politicise everyday strategies of making visible oppressive conditions and alternatives. For example, the oft cited statement by Black lesbian feminist Audre Lorde from her book A Burst of Light (1988) 'Caring for myself is not self-indulgence, it is self-preservation, and that is an act of political warfare' (cited in Ahmed, 2014). 
Ahmed (2014) exposes the social privilege that is assumed in notions of self-care and instead takes up Lorde's insistence that care for the self is political and a matter of survival for those who have not been afforded value because of race, gender, sexuality and class. In her powerful essay Self-care as Warfare, Ahmed (2014) says, in queer, feminist and anti-racist work self-care is about the creation of community, fragile communities, assembled out of the experiences of being shattered. We reassemble ourselves through the ordinary, everyday and often painstaking work of looking after ourselves; looking after each other. This is why when we have to insist, I matter, we matter, we are transforming what matters. Mindshackles' exploration opens up different ways of engaging with the politics of selfcare that brings into view embodied moments, voices and images of everyday experiences that are produced through human and non-human assemblages that can sustain or undo wellbeing.

\section{Concluding Remarks}

Exploring the digital practices and cultural making of Mindshackles has been a focal point for writing through this creative-academic assemblage. Our collaborative approach has sought to identify the challenges of creating public stories and images of recovery from depression to hold open spaces through which to reimagine women's lives. Theorising creativity as an assemblage provides a useful way of situating stories of recovery that make visible leisure practices within the growing area of digitalised mental health promotion and intervention. Through Tricia's account we see the embodiment of dance as a spatial, (Black) historical and cultural practice that figures as a significant 
affective "infrastructure of care" sustaining emotional life (Butler, 2014). Against the pervasiveness of medicalised, individualized and pathologized histories that are entangled in the whiteness of mental health and recovery services, Mindshackles' offers a site of digital "cultural making" (Swist et al., 2017) where the intensities of "feeling alive" are forged through text, image and sound; memories, objects, spaces, bodies and technologies entangle to create other possibilities for living. These citizen led public spaces importantly diversify the digital mental health landscape by re-presenting experiences beyond biochemical deficits or neoliberal prescriptions for "happiness", and thus move beyond the limitations of a medicalised imagination.

\section{References}

Ahmed, S. (2017). Living a Feminist Life. Durham, NC: Duke University Press.

Ahmed, S. (2014). Self-care as warfare. Retrieved from

https://feministkilljoys.com/2014/08/25/selfcare-as-warfare/ [accessed 28/7/2017].

Ahmed, S. (2004). The cultural politics of emotion. Edinburgh: Edinburgh University Press.

Berbary, L. A. (2015). Creative analytic practices : Attachments, uses and constructions within humanist qualitative leisure research. International Leisure Review, (2), 27-55. https://doi.org/10.6298/LLR.2015.4.11 
Boydell, K. M., Hodgins, M., Gladstone, B. M., Stasiulis, E., Belliveau, G., Cheu, H., ... Parsons, J. (2016). Arts-based health research and academic legitimacy: transcending hegemonic conventions. Qualitative Research,

\section{https://doi.org/10.1177/1468794116630040}

Butler, J. (2014). Rethinking Vulnerability and Resistance. In Plenary Conference at the XV Simposio de la Asociación Internacional de Filósofas (IAPh), Universidad de Alcalá (Madrid), 24th June (pp. 1-19). Retrieved from

http://www.institutofranklin.net/sites/default/files/files/Rethinking Vulnerability and Resistance Judith Butler.pdf

Cvetkovich, A., (2012). Depression: A public feeling. Durham: Duke University Press.

Duff, C., \& Sumartojo, S. (2017). Assemblages of creativity: Material practices in the creative economy. Organization, 24(3), 418-432.

Duff, C. (2014). Assemblages of Health: Deleuze's empiricism and the ethology of life: Rotterdam: Springer.

Fox, N., \& Alldred, P. (2016). Sociology and the New Materialism. London: Sage.

Fox, N. (2015). Creativity, anti-humanism and the "new sociology of art." Journal of Sociology, 51(3), 522-536. 
Fox, N. J. (2012). Creativity and health: an anti-humanist reflection. Health (London, England: 1997), 17(5), 495-511. https://doi.org/10.1177/1363459312464074

Fullagar, S. (forthcoming). Diffracting mind-body relations: Feminist materialism and the entanglement of physical culture in women's recovery from depression. In J. Newman, H. Thorpe, \& D. Andrews (Eds.), Moving Body: Sporting Ecologies, Assemblages, and New Materialisms (pp. 1-37). New Brunswick, NJ: Rutgers University Press.

Fullagar, S. (2017). Post-qualitative inquiry and the new materialist turn: Implications for sport, health and physical culture research,. Qualitative Research in Sport, Exercise and Health, 9(2), 247-257.

Fullagar, S., Rich, E., \& Francombe-Webb, J. (2017). New kinds of (ab)normal?: Public pedagogies, affect and youth mental health in the digital age. Social Sciences. 6(3), 99; doi: $\underline{10.3390 / \text { socsci6030099 }}$

Fullagar, S., \& O'Brien, W. (2014). Social recovery and the move beyond deficit models of depression: A feminist analysis of mid-life women's self-care practices. Social Science and Medicine, 117, 116-124. 
Fullagar, S., \& O'Brien, W. (2012). Immobility, battles, and the journey of feeling alive: women's metaphors of self-transformation through depression and recovery. Qualitative Health Research, 22(8), 1063-72.

Fullagar, S. (2008a). Sites of somatic subjectivity: E-scaped mental health promotion and the biopolitics of depression. Social Theory \& Health, 6(4), 323-341.

Fullagar, S. (2008b). Leisure practices as counter-depressants. Leisure Sciences, $30(1), 1-18$.

Grey, F. (2017). Benevolent othering: Speaking positively about mental health service users, Philosophy, Psychiatry, \& Psychology, 23(3), 241-251.

Healy, D. (1998). The Anti-Depressant Era. Cambridge: Harvard University Press.

Keller, J. (2015). Girls' Feminist Blogging in a Postfeminist Age. Routledge: London.

Kumm, B., \& Johnson, C. (2017). Subversive imagination: Smoothing space for leisure, identity, and politics. In K. Spracklen, B. Lashua, E. Sharpe, \& S. Swain (Eds.), The Palgrave handbook of leisure theory (pp. 891-910). London: Palgrave. 
Lafrance, M. N., (2011). Reproducing, resisting and transcending discourses of femininity: a discourse analysis of women's accounts of leisure. Qualitative Research in Sport, Exercise and Health, 3(1), 80-98.

McManus S, Bebbington P, Jenkins R, Brugha T. (Eds.) (2016). Mental health and wellbeing in England: Adult Psychiatric Morbidity Survey 2014. Leeds: NHS Digital.

McLeod, K. (2017). Wellbeing Machine: How health emerges from the assemblages of everyday life. Durham, NC: Carolina Academic Press.

Lorde, A. (1988). A burst of light: Essays. Ithaca, NY: Firebrand Books.

Parry, D. C. (2013). Women's mental health and the power of leisure. In V. Freysinger, S. M. Shaw, K. A. Henderson, \& D. Bialeschki (Eds.), Leisure, Women and Gender (pp. 215-228). Urbana, IL: Venture Publishing Inc.

Parry, D. C., \& Johnson, C. W. (2007). Contextualizing leisure research to encompass complexity in lived leisure experience: The need for creative analytic practice. Leisure sciences, 29(2), 119-130.

Rich, E., \& Miah, A. (2017). Mobile, wearable and ingestible health technologies: towards a critical research agenda. Health Sociology Review, 26(1), 84-97. 
Richardson, L. (2000). New writing practices in qualitative research. Sociology of Sport Journal, 17(1), 5-20.

Ridge, D., \& Ziebland, S. (2012). Understanding depression through a "coming out" framework. Sociology of Health and IIIness, 34(5), 730-745.

Rose, D. (2017). Service user/survivor-led research in mental health: epistemological possibilities. Disability \& Society, 32(6), 1-17.

https://doi.org/10.1080/09687599.2017.1320270

Sjollema, S., \& Yuen, F. (2017). Evocative words and ethical crafting: Poetic representation in leisure research. Leisure Sciences, 39(2), 109-125.

St. Pierre, E. A. (2014). A brief and personal history of post qualitative research: toward "post inquiry." Journal of Curriculum Theorizing, 30(2), 2-19.

Swist, T., Hodge, B., \& Collin, P. (2016). "Cultural making": how complexity and power relations are modulated in transdisciplinary research. Continuum, 30(4), 489-501.

Teghtsoonian, K. (2009). Depression and mental health in neoliberal times: A critical analysis of policy and discourse. Social Science and Medicine, 69(1), 28-35. 
Voronka, J. (2016). The politics of 'people with lived experience': Experiential authority and the risks of strategic essentialism. Philosophy, Psychiatry, \& Psychology, 23(3), 189-201.

Ussher, J. (2011). The Madness of Women: Myth and Experience. London: Routledge. 